\title{
Signaling Proteins and Transcription Factors in Normal and Malignant Early B Cell Development
}

\author{
Patricia Pérez-Vera, ${ }^{1}$ Adriana Reyes-León, ${ }^{1}$ and Ezequiel M. Fuentes-Pananá ${ }^{2}$ \\ ${ }^{1}$ Laboratorio de Cultivo de Tejidos, Departamento de Investigación en Genética Humana, \\ Instituto Nacional de Pediatría Insurgentes Sur 3700-C. Col. Insurgentes Cuicuilco, 04530 México, DF, Mexico \\ ${ }^{2}$ Unidad de Investigación Médica en Enfermedades Infecciosas y Parasitarias (UIMEIP), \\ Hospital de Pediatría Centro Médico Nacional Siglo XXI, Instituto Mexicano del Seguro Social, Avenida Cuauhtémoc 330, \\ Colonia Doctores, Delegación Cuauhtémoc, 06720 México, DF, Mexico
}

Correspondence should be addressed to Ezequiel M. Fuentes-Pananá, empanana@yahoo.com

Received 11 March 2011; Accepted 8 April 2011

Academic Editor: Philip L. McCarthy

Copyright (c) 2011 Patricia Pérez-Vera et al. This is an open access article distributed under the Creative Commons Attribution License, which permits unrestricted use, distribution, and reproduction in any medium, provided the original work is properly cited.

B cell development starts in bone marrow with the commitment of hematopoietic progenitors to the B cell lineage. In murine models, the IL-7 and preBCR receptors, and the signaling pathways and transcription factors that they regulate, control commitment and maintenance along the B cell pathway. E2A, EBF1, PAX5, and Ikaros are among the most important transcription factors controlling early development and thereby conditioning mice homeostatic B cell lymphopoiesis. Importantly, their gain or loss of function often results in malignant development in humans, supporting conserved roles for these transcription factors. B cell acute lymphoblastic leukemia is the most common cause of pediatric cancer, and it is characterized by unpaired early B cell development resulting from genetic lesions in these critical signaling pathways and transcription factors. Fine mapping of these genetic abnormalities is allowing more specific treatments, more accurately predicting risk profiles for this disease, and improving survival rates.

\section{Introduction}

The main function of mature immunocompetent B cells is to make antibodies; therefore, they are responsible for the adaptive humoral immune response. Formation of these mature B cells is a highly ordered multistep process that in adult mammals starts in bone marrow with the commitment of hematopoietic stem cells to the B cell lineage and ends with formation of mature B cells in secondary lymphoid organs. This developmental process was once thought to be inflexible, unidirectional, and irreversible, but recent lines of evidence support a higher level of plasticity to the differentiating cell. Several transcription factors (TFs) play critical roles in commitment and maintenance along the B cell pathway, and their gain or loss affects homeostatic B cell lymphopoiesis and often results in malignant transformation.

\section{The Early Stages of B Cell Development}

B cells express receptors (BCRs) to various antigens; each BCR is uniquely specialized to recognize and counteract a particular new or recurrent pathogen. The main goal of B cell development is to generate $\mathrm{B}$ cells expressing a diverse repertoire of BCRs. This receptor is a membrane-bound immunoglobulin (Ig) consisting of a heterodimer of identical pairs of the Ig heavy and light chains, which are responsible for the clonal diversity of the B cell repertoire. The Ig heavy and light chain heterodimer is, however, unable to generate signals to trigger biological responses after antigen binding; this function is mediated by the disulfide-coupled heterodimer of $\operatorname{Ig} \alpha(\mathrm{CD} 79 \mathrm{a})$ and $\operatorname{Ig} \beta(\mathrm{CD} 79 \mathrm{~b})$, which is noncovalently associated with the Ig antigen recognition unit [1]. It is the sequential expression and assembly of these BCR components that defines each developmental stage, and, therefore, each stage is characterized by a particular form 

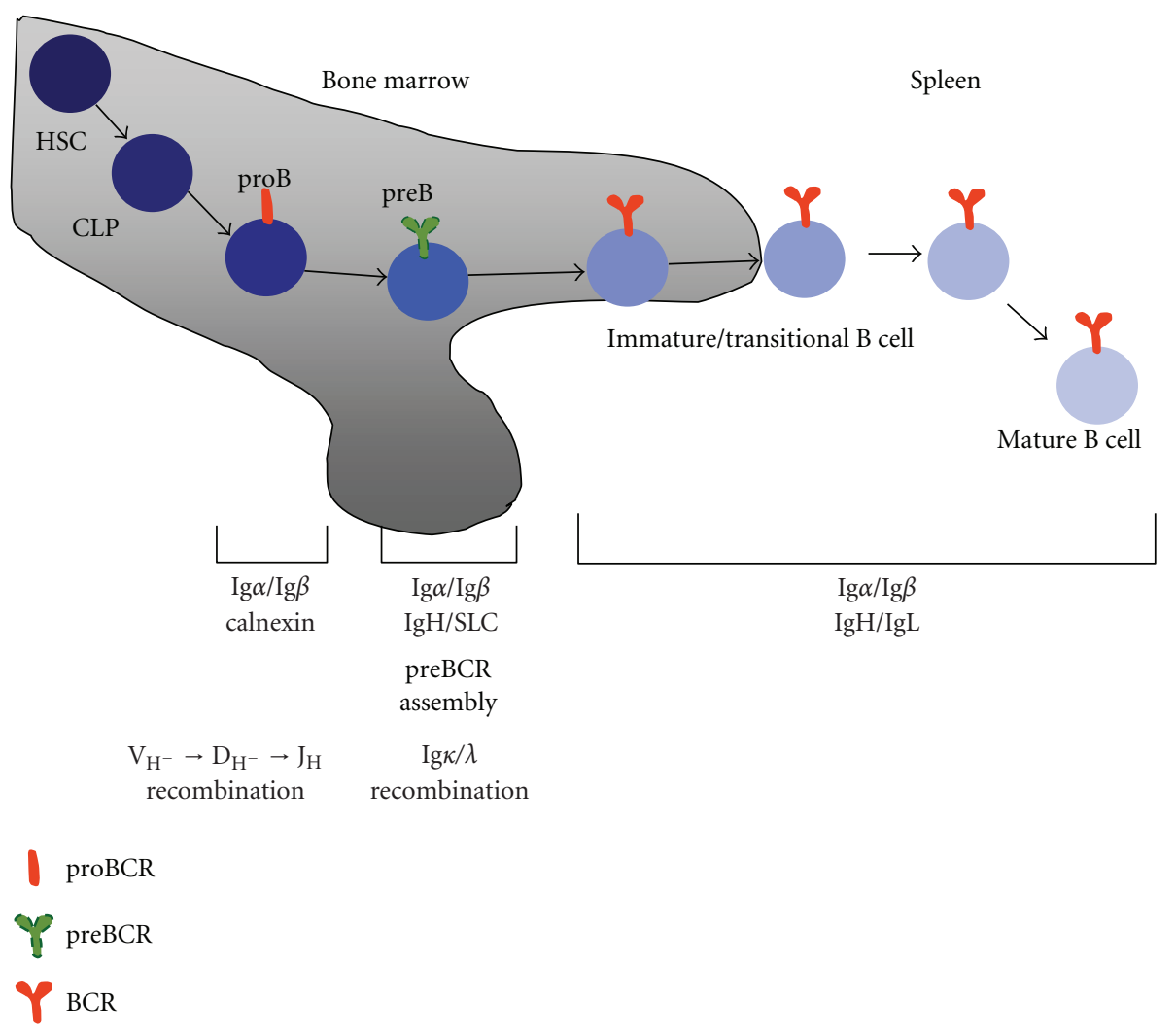

FIGURE 1: B cell development in adult mammals starts in bone marrow with the commitment of hematopoietic stem cells (HSCs) to the B cell lineage and ends with formation of mature B cells in peripheral secondary lymphoid organs (e.g., the spleen). It is the sequential expression and assembly of the components of the B cell antigen receptor (BCR) what defines each developmental stage. The first stage exhibiting commitment to the B cell lineage is the proB, and here the immunoglobulin heavy chain is in the process of recombination, and the signaling proteins $\operatorname{Ig} \alpha$ and $\operatorname{Ig} \beta$ are in surface forming complexes with chaperon proteins like calnexin (the proBCR). The next developmental stage, the preB, happens after the heavy chain was successfully recombined and the preBCR is assembled. In this stage, the light chain is recombined and unrearranged heavy chain alleles are excluded. After light chain recombination and pairing with the heavy chain and $\operatorname{Ig} \alpha$ and $\operatorname{Ig} \beta$ the mature BCR is formed, the B cell is in the immature (in bone marrow) and transitional (in periphery) stages. Here, B cell mechanisms of self-tolerance are active allowing self- and nonself-recognition by the mature B cell. Transition to the mature stage happens if the BCR of the immature/transitional B cell does not find its cognate antigen after several days of bone marrow and peripheral trafficking.

of the BCR, reflecting the progression of receptor assembly (Figure 1) [2, 3].

To achieve BCR clonal diversity, the Ig heavy and light chain genes are composed of constant and variable regions. The variable region is formed by a series of segments termed $\mathrm{V}$ (variable), D (diversity), and J (joining) (Figure 2(a)), which are brought together by a site-specific recombination process termed VDJ recombination. This is a highly ordered process during which the $\mathrm{D}$ and $\mathrm{J}$ fragments are rearranged and the V segment is then joined to the DJ fragment; these steps occur first in the heavy and then in the light chain loci (Figure 2(b)) $[4,5]$. This process is essential for the lymphocyte's adaptive immune function. The first developmental stage exhibiting commitment to the B cell lineage is called proB and is characterized by rearrangement of the Ig heavy chain [2]. The proB stage is further divided according to the status of the heavy chain; in mice, Marshall named these substages proB-A (during which the heavy chain is in the germ line state), B (during which D and J are recombined), and $\mathrm{C}$ (during which V-DJ is recombined) [6]. These stages are better known in humans as early proB or preproB (A), proB (B) and preB I (C) (Figure 2(b)).

In the proB stage $\operatorname{Ig} \alpha$ and $\operatorname{Ig} \beta$ are expressed at the cell surface in association with chaperon proteins such as calnexin [7]. As soon as the heavy chain is successfully recombined, it is assembled with $\operatorname{Ig} \alpha$ and $\operatorname{Ig} \beta$ and the surrogate light chains $\lambda 5$ and VpreB to form the preBCR. Surface expression of this receptor marks the transition to the preB stage (Figure 1) [5]. Unsuccessful recombination (with heavy chain VDJ fragments that are not in a proper reading frame) or unsuccessful pairing of the preBCR components results in proB cells that are unable to proceed to the preB stage and leads to apoptosis. This observation supports an active signaling role for the preBCR in generating the permissive signal that allows differentiation through the preB stage. In the preB stage, the light chain $\mathrm{V}$ and $\mathrm{J}$ fragments are recombined, and, again, successful assembly of the mature form of the BCR marks the transition to the immature stage (Figures 1 and 2(b)) $[2,4,8,9]$.

In addition to their VDJ recombination status, all proB and preB stages can be recognized by their patterns of surface 

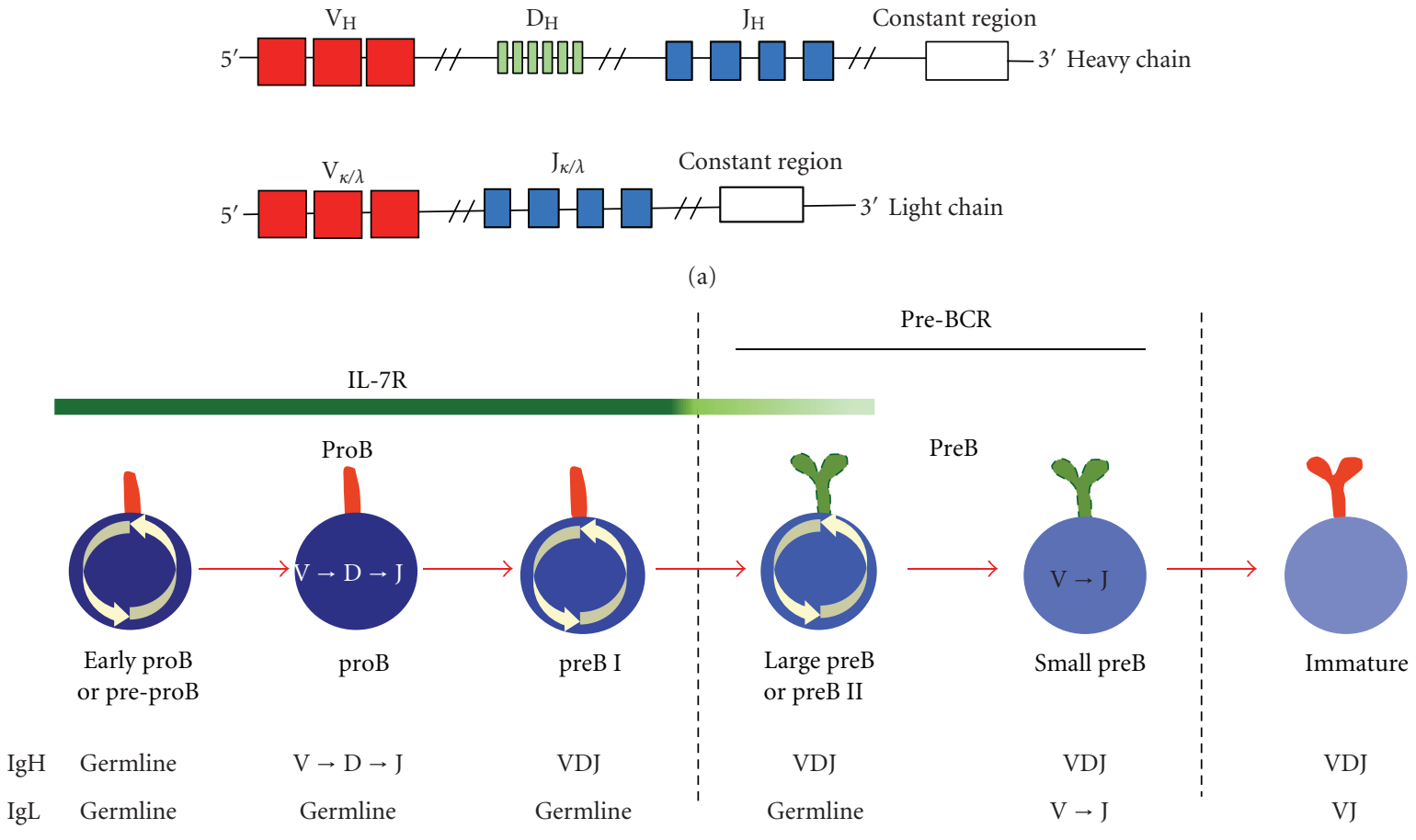

(b)

FIGURE 2: (a) The Ig heavy and light chain genes are comprised of constant and variable regions, where the variable region is formed by an $n$ number of segments termed V (variable), D (diversity), and J (joining) in the heavy chain and by segments V and J in the light chain. These segments are brought together by a site-specific recombination process termed VDJ recombination responsible for the extensive repertoire of BCR specificities. There are two loci for light chain, $\kappa$ and $\lambda$. Here, all the loci are shown in germline configuration, previous to the process of VDJ recombination. (b) The early stages of B cell development are differentiated by the process of VDJ recombination, and the heavy (IgH) and light (IgL) chains are recombined in the proB and preB stages, respectively. Each stage is further subdivided according to the sequential assembly of the VDJ segments. Replication and recombination processes are mutually exclusive as denoted by the circular arrows and VDJ signs inside the cell. Dashed lines separating proB and preB stages indicate checkpoints where signaling from the preBCR and BCR is required for positive selection and progression along the B cell maturation pathway. Continuous lines indicate the main receptors controlling each developmental stage. The differential intensity in the IL-7 green line indicates the sub-stages where a higher or lower concentration of the IL-7R ligand is required.

markers expression and their proliferative state [6]. Because DNA replication during proliferation is associated with homologous recombination and VDJ rearrangement is associated with nonhomologous recombination, these two processes are mutually exclusive. ProB and preB stages are thus characterized by waves of VDJ recombination followed by waves of proliferation $[6,10]$. To achieve this pattern, the expression of the two main enzymes responsible for VDJ rearrangement, the recombinase associated genes 1 and 2 (RAG1 and RAG2), are tightly regulated during the cell cycle; they are highly active in G0 and degraded before entrance into S phase [11-13]. The developing B cell thereby ensures that no events of non-homologous recombination will occur during DNA replication and avoids an increase in the mutation rate. This fine regulatory control separating proliferation and differentiation could explain why the proliferative proB and preB substages are often found to be compromised in B cell acute lymphoblastic leukemia (ALL) and why leukemic cells are often unable to differentiate. In proB, proliferative stages occur in early proB or preproB (before heavy chain recombination) and preB-I (after heavy chain recombination), whereas in preB proliferation occurs during the large preB-II stage (before light chain rearrangement) (Figure 2(b)) $[6,10]$.

\section{Regulation of Lineage Commitment: The Critical Role of IL-7R, PreBCR, and Downstream B cell Transcription Factors}

Limitation of lineage choice during development is regulated by a combination of signaling pathways and transcription factors (TFs). In mice, the main receptor controlling the proB stage is the IL-7R, which is composed of an $\alpha$ chain (IL-7R $\alpha$ ) and the common cytokine receptor $\gamma$ chain $(\gamma \mathrm{c})[14,15]$. Deletion of IL-7R $\alpha$ or $\gamma$ c leads to developmental arrest at the early proB stage [16-19]. Loss of IL-7 also affects T cell development; however, this can be overcome by enforced expression of $\mathrm{Bcl} 2$, supporting a key role in proT and preT survival $[20,21]$. On the other hand, enforced expression of antiapoptotic genes cannot compensate for IL-7R loss in $\mathrm{B}$ cell development, indicating additional roles for IL-7 in this lineage [22]. In humans, B cells can still be generated in severe combined immunodeficiency (SCID) patients with mutations in the $I L-7 R$ gene, suggesting that IL-7 signaling is 
not as essential for human B cell development [23]. However, a recent study has demonstrated that in vitro human $\mathrm{B}$ cell production is IL-7 dependent [24].

IL-7 activates three major signaling pathways: (1) JAKSTAT, (2) phosphatidylinositol 3-kinase (PI3K)-Akt, and (3) Ras-Raf-Erk [25]. STAT5 (signal transducer and activator of transcription 5) is the predominant STAT protein activated by IL-7 $[25,26]$. STAT5 is a transcription factor that consists of two highly related isoforms, STAT5A and STAT5B; these proteins play redundant roles because the loss of only STAT5A or STAT5B has minor consequences for lymphocyte function [26]. However, when both STAT5s are lost, B cell development is arrested at the early proB stage, indicating that STAT5 is an essential mediator of IL-7 signaling in early B cell development $[27,28]$. IL-7/STAT5 signaling also promotes cell survival via the activation of the anti-apoptotic gene $M c 1$ [29]. Once the preBCR is expressed, it can take over many of the functions performed by the IL-7 receptor. The preBCR can signal constitutively or when activated by binding to nonpolymorphic ligands; like IL-7R, it activates the PI3K-Akt and Ras-Raf-Erk pathways $[8,30]$. It has been shown that proliferation of large preB-II cells is dependent on the preBCR acting in concert with low (picogram) levels of IL-7 (Figure 2(b)) [31]. The CCND3 gene, which encodes for cyclin D3, is essential for pre-B cell expansion and integrates IL-7R and preBCR signals [32].

Downstream of the IL-7 and preBCR receptors, a handful of TFs have been observed to be critical for commitment to the $\mathrm{B}$ cell lineage and early development; these include E2A/TCF3 (immunoglobulin enhancer binding factors E12/E47/transcription factor 3), EBF1 (Early B cell Factor 1), and PAX5 (Paired box 5) [33-35]. Loss of E2A and EBF1 blocks entry into the $\mathrm{B}$ cell lineage, and loss of PAX5 redirects B cells into other lineages [35-37]. Thus, there is a hierarchical relationship in the expression of these transcription factors, with some genes regulating entry into the $\mathrm{B}$ cell lineage and others regulating commitment to this lineage [36, 38-40]. Ig recombination generally correlates with germline transcription; transcription probably allows changes in the chromatin structure and/or RAGs accessibility [5]. One of the main molecular functions of PAX5 (acting together with E2A, EBF1 and STAT5) is to allow VDJ recombination [41-43]. Ectopic expression of PAX5 and E2A allows VDJ recombination in non-B cells [44, 45]. Also, E2A, PAX5, IKZF1, and RUNX1, among other TFs, are responsible for RAG expression [46, 47]. Therefore, IL-7R signaling fulfills an essential role in early B cell development, with STAT5 participating in the activation of the $B$ cell regulatory genes E2A, EBF1, and PAX5 [37].

$E 2 A$ encodes two TFs via alternative splicing, E12 and E47. In mice lacking the E2A gene, the B cell lineage is lost, there is no heavy chain recombination, and the expression of the B-cell-restricted genes EBF1, PAX5, CD79A/B, IGLL1, and VPREB1 (CD179A) is also affected $[48,49]$. The absence of the E47 isoform results in a diminished $\mathrm{B}$ cell population, suggesting a significant role for E47 homodimers in differentiation. In contrast, the lack of E12 results in normal but inefficient $\mathrm{B}$ cell differentiation [50]. Loss of EBF1 results in $\mathrm{B}$ cell arrest before heavy chain recombination and failure to express the preBCR components $\operatorname{Ig} \alpha$ and $\operatorname{Ig} \beta$ and the surrogate light chains $\lambda 5$ and VPREB [51]. Enforced expression of EBF1 and PAX5 is sufficient to overcome the developmental block in mice deficient in E2A, IL-7, or IL$7 \mathrm{R} \alpha$, further illustrating the transcriptional hierarchy of the B-cell specific program triggered by IL-7 receptor signaling $[37,52-56]$.

The EBF1 promoter is responsive to PAX5, ETS1, and SP11 (PU.1) and together with PAX5 drives the expression of many genes critical for early $B$ cell development and B cell function, including FOXO1, MYCN, LEF1, BLNK, CD79A (MB-1), RAG2, CD19, and CR2 (CD21) [37, 51, 57]. EBF1 also works at an epigenetic level, controlling chromatin structure by recruitment of molecules as RUNX1 and Eproteins $[40,58]$. EBF1 expression has been implicated in demethylation of the $C D 79 A$ promoter, and together with PAX5 and other transcriptional activators, it generates genomic regions of active chromatin [59]. PAX5 can be a positive or negative regulator depending on the transcriptional context [60]; it is generally a positive regulator of B-cell-specific genes such as EBF1, CD19, MB-1, BLNK, IGLL5, and VPREB1 [34, 61] and a repressor of non Blineage genes such as M-CSR, NOTCH1, and FLT3 [6264]. Genome-wide transcriptional analysis has identified a plethora of genes targeted by both EBF1 and PAX5, which cooperate to activate the $\mathrm{B}$ cell gene expression program and to allow lineage maintenance by inhibiting the expression of genes associated with other developmental programs and hematopoietic progenitors $[65,66]$. Because of EBF1 and PAX5-mediated transcription of B-cell-specific genes and repression of genes associated with other lineages, B cell development is unidirectional and perhaps irreversible in homeostatic conditions [34, 36, 59, 63, 67, 68].

Also important for lymphoid development are members of the Ikaros family of TFs, mainly IKZF1 (which encodes Ikaros) and IKZF3 (which encodes Aiolos); both TFs bind to the same consensus sequence as either homodimers or heterodimers playing distinct roles in $\mathrm{B}$ and $\mathrm{T}$ cell differentiation $[69,70]$. Ikaros activates $C D 19$ and represses genes that are unrelated to the B lineage, such as CD4 [71]. Expression of IKZF1 and IKZF3 is regulated by alternative splicing, which produces long isoforms (Ik-1, Ik-2, Ik-3, Aio1, Aio-3, Aio-4, and Aio-6) that have at least three zinc fingers and efficiently bind to DNA, and short isoforms (Ik-4, Ik-5/7, Ik-6, Ik-8, Aio-2, Aio-5) that have less than two zinc finger domains, are unable to bind DNA with high affinity, and do not activate transcription; these short forms, therefore, act as dominant negatives [69, 72, 73]. Ikaros is activated in early stages of lymphopoiesis and is required for both early and late events in lymphocyte differentiation. Ikaros and Helios (another member of the Ikaros family; IKZF2) have opposite regulatory roles of the expression of INPP5D gene encoding the SHIP phosphatase, a BCR signaling negative regulator [74]. Aiolos is not required during the early specification of the $\mathrm{B}$ and $\mathrm{T}$ lineages but is essential during $\mathrm{B}$ cell maturation [75]. Aiolos together with Ikaros act in concert to repress c-Myc expression in large preB cells with concomitant repression and induction of genes CCND3 and CDKNIB, respectively [76], thus promoting 
preB cell cycle exit and transition to small preBs where light chain recombination occurs. Therefore, Aiolos has a role during $\mathrm{B}$ cell commitment and together with Ikaros during $\mathrm{B}$ cell maintenance, hence, mice lacking Ikaros lack all lymphoid lineages $[77,78]$, whereas Aiolos-deficient mice have an increased pre-B cell population and develop B cell lymphomas [75].

\section{Genetic Abnormalities in Human Pediatric B Cell Acute Lymphoblastic Leukemia}

Because all these TFs are critical for early murine B cell development, it is not surprising that abnormalities in these genes have often been found in human B cell acute lymphoblastic leukemia (B-ALL). ALL is the most common childhood cancer and is characterized by impaired early lymphoid development. ALL can be classified as B or T cell ALL; B-ALL is the one most frequently found (83\% of ALLs and $30 \%$ to $40 \%$ of all childhood cancers) $[79,80]$. A high percentage of B cell ALL patients have genetic lesions (mostly chromosomal translocations) that are specifically associated with the leukemic cells. In recent years, efforts have focused on the identification of the specific developmental stage where the ALL cells are arrested and the genetic lesions responsible for the leukemia phenotype. These data have helped to classify the disease, stratify the patients into risk groups and design specific therapies that have significantly improved the survival rate $[65,66]$.

RUNX1 (Runt-related transcription factor 1) is a frequent target for chromosomal rearrangements and mutations in ALL. RUNX1 ( $A M L 1$ or $C B F \alpha 2)$ encodes a TF that possesses a Runt domain, which is essential for interaction with $\mathrm{CBF} \beta$, a heterodimer that regulates transcription of genes that are important in hematopoiesis. CBF cooperates to regulate the survival of early pro-B cells and establish a Blineage-specific transcriptional program [81]. A substantial proportion (25\% of children and $2 \%$ of adults) of ALL patients present the ETV6/RUNX1 fusion as a result of the translocation $\mathrm{t}(12 ; 21)(\mathrm{p} 12 ; \mathrm{q} 21)$. In contrast to the normal function of this TF, the chimeric protein recruits corepressors and histone deacetylases to create stable repression complexes at the promoters of RUNX1 target genes [82]. Homozygous mutations in RUNX1 in mice are lethal, with embryos lacking fetal liver hematopoiesis $[83,84]$. This result supports the idea of different roles for this TF in mice and humans and suggests that RUNX1 plays a more profound role at an earlier stage of murine hematopoiesis.

The TF E2A has been found in various chromosomal translocations; among the most common are $\mathrm{t}(1 ; 19)(\mathrm{q} 23 ; \mathrm{p} 13)$, which results in the $E 2 A-P B X 1$ fusion, and $\mathrm{t}(17 ; 19)(\mathrm{q} 22 ; \mathrm{p} 13)$, resulting in E2A-HLF (hepatic leukemia factor). These abnormalities are detected in 5-6\% and $1 \%$ of children ALL, respectively, and are found in less than $5 \%$ of adult cases $[37,85]$. These fusion products possess properties that the original proteins do not have. E2A-PBX1 consists of the E2A N-terminal TF domain fused to the Hox cooperative motif and homeodomain of C-terminal PBX1. PBX1 modulates the DNA binding activity of specific subsets of Hox proteins, which participate in normal hematopoiesis, and the chimeric protein E2A-PBX1 may disturb Hox activity $[37,85]$. E2A-PBX1 is considered a potent transcriptional activator of the WNT16 gene; because the WNT family is widely known to be involved in oncogenesis, impairment of WNT signaling could be a mechanism of leukemia initiation [86]. E2A-HLF encodes a chimeric protein that contains the E2A N-terminal fused to the C-terminal basic leucine zipper of HLF. E2A-PBX1 and E2A-HLF fusion proteins do not bind the same DNA motifs and might regulate different sets of genes, disturbing different processes. E2A-HLF promotes the enhanced survival of early B cells activating expression of the anti-apoptotic TFs SNAI2 (SLUG) and LMO2, accordingly, gene silencing of LMO2 in an E2A-HLF ${ }^{\text {os }}$ cell line-induced apoptotic cell death [87].

The MLL (mixed lineage leukemia) gene is often rearranged in patients with ALL, both de novo and therapyrelated. Leukemias with MLL translocations can be myeloid or lymphoid and often tend to express both lineage markers, probably indicating a very early multipotent progenitor origin $[88,89]$. Today, more than 50 fusions involving $M L L$ have been documented. The translocation $\mathrm{t}(4 ; 11)(\mathrm{q} 21 ; \mathrm{q} 23)$ that fuses the MLL and AF4 genes is present in the majority of the de novo cases and represents up to $80 \%$ of the infant, $2 \%$ of children older than 1-year old, and 5 to $10 \%$ of adult ALLs. MLL possesses a Trithorax domain that participates in the methylation of lysine 4 of histone $\mathrm{H} 3$ (H3K4), and this function is associated with transcriptional activation of target promoters; important for leukemogenesis are HOX genes and Meis1. Hox proteins are a highly conserved homeobox containing family of TFs that regulates cell fate, including hematopoietic lineage decisions [88-90]. Recent data show that MLL and MLL-fusion proteins are recruited to the target genes by the transcriptional elongation factor Paflc, and this interaction is required to increase the expression of $\mathrm{HOX}$ genes and transformation of bone marrow cells [90].

Another important translocation is $\mathrm{t}(9 ; 22)(\mathrm{q} 34 ; \mathrm{q} 11)$ (also known as Philadelphia chromosome), which fuses the genes $B C R$ and $A B L 1$ and is found in 5\% of childhood and $25 \%$ of adult B cell ALL. Unregulated expression of STAT5 has been observed to be associated with $B C R-A B L 1$ [91, 92]. STAT5 inactivation results in cell cycle arrest and apoptosis of BCR-ABL1 ${ }^{\text {pos }}$ malignant B cells, and BCR-ABL1 expression is unable to induce leukemia in STAT $5^{-/-}$mice, supporting an important role for STAT5 in the initiation of BCR-ABL1 ${ }^{\text {pos }}$ transformation. Genome-wide analysis of $B$ cell ALL has identified mutations in the Janus kinases (JAK1 and JAK2) in up to $10 \%$ of patients [92]. Interestingly, patients with $J A K 1 / 2$ mutations and patients with the $B C R-A B L 1$ fusion both have a similar gene expression profile and a highrisk prognosis [91]. JAK1 and 2 are activated after IL-7R engagement and mediate STAT5 activation; most mutations in these proteins occur in the kinase domain, constitutively activating the JAK-STAT signaling pathway. JAK gain-offunction mutations are insufficient to confer a transformed phenotype, and it has been demonstrated that 100\% of BALL cases with JAK2 mutations overexpress CRLF2 (type I cytokine receptor subunit, also known as thymic stromal lymphopoietin receptor) [66]. CRFL2 forms a heterodimeric 


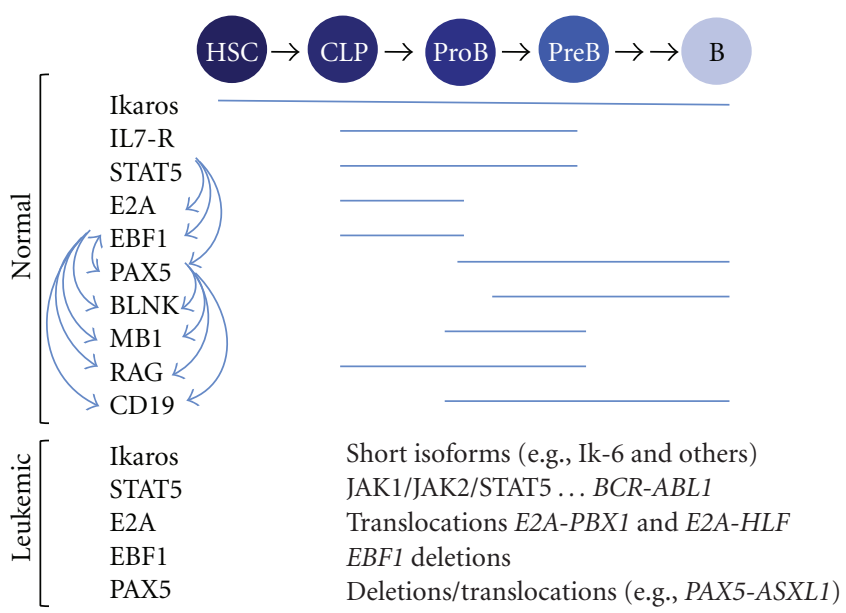

FIGURE 3: Homeostatic and leukemic expression of receptors, signaling proteins, and transcription factors along the $\mathrm{B}$ cell pathway. Developmental stages are indicated starting with the hematopoietic stem cell (HSC), the common lymphoid progenitor (CLP), and into the B cell pathway, stages proB, preB, and mature $\mathrm{B}$ cells. Normal gene expression along the developmental pathway is indicated with blue bars, and expression dependency between proteins is indicated with arrows. Most common modified forms of these receptors, signaling proteins, and transcription factors associated with acute lymphoblastic leukemia are also indicated.

complex with the IL-7R and is overexpressed in $15 \%$ of BALL cases as a result of translocations or intrachromosomal deletions [66, 92]. In a subset of cases, CRLF2 acquires a Phe232Cys gain-of-function mutation that promotes constitutive dimerization and cytokine-independent proliferation [92]. In agreement with data suggesting an association between CRLF2 and the JAK-STAT signaling pathway in BALL, the gene profile associated with CRLF2 over-expression is also highly similar to that found in BCR-ABL1 ${ }^{\text {pos }} \mathrm{B}$ ALL. In a subgroup of aggressive treatment-resistant B ALL, deregulation of the JAK-STAT pathway is associated with abnormalities in genes such as IKZF1 and CDKN2A/B [66, 91, 92].

Genome-wide analysis has also identified abnormalities in PAX5 and EBF1 in B ALL [93]. In the case of PAX5, these abnormalities are generally (a) point mutations located in exons $2,3,4,5,6,7,8,9$, and 10 , most of which are clustered within functional domains or (b) alterations in the expression of splice variants of PAX5 $[94,95]$. These alterations have been found in up to $32 \%$ of children and $30 \%$ of adults with B ALL and in 35\% of relapsed cases [93, 96, 97]. Almost 35\% of patients with PAX5 lesions lack expression of the full-length protein and express only short variants [95]. Mullighan et al. reported PAX5 deletions in $51 \%$ of BCR-ABL1 ${ }^{\text {pos }}$ B ALL cases [91]. However, the specific association between aberrant splicing and PAX5 mutations with specific genetic subtypes of B ALL is controversial [95]. In addition, PAX5 (9p11) participates in gene fusions. Currently, five $P A X 5$ fusions have been identified, with the gene partners LOC392027 (7p12.1), SLCO1B3 (12p12), ASXL1 (20q11.1), KIF3B (20q11.21), and C20orf112 (20q11.1). All of the resulting chimeric proteins retain the paired domain of the TF, and, as for the previously described deletions, the gene fusions result in lowered expression of PAX5 and its target genes [98]. EBF1 alterations are also common in patients with poor outcomes. In a cohort of 45 adolescent and adult ALL cases, deletions in EBF1 were observed in $4.4 \%$ of cases; in relapsed children, EBF1 deletions are particularly frequent (25\%), suggesting a possible contribution of this TF for the development of relapse and a potential prognostic value $[65,66,97,99]$.

High expression levels of the short Ikaros isoforms, particularly the dominant negative Ik-6, are also associated with high risk leukemia [100-105]. However, recent reports have showed that all Ikaros isoforms are expressed in patients with B ALL, although their level of expression differs [106]. Most of the BCR-ABL1 ${ }^{\text {pos }}$ B ALL patients have deletions in IKZF1 and increased levels of the short isoforms; however, Ik- 6 has also been found to be elevated in BCR-ABL1 ${ }^{\text {neg }}$ patients. In all these cases, deletion in the IKZF1 gene is associated with a poor outcome; therefore, Ikaros isoform expression is an important prognostic factor in BCR-ABL1 ${ }^{\text {pos }}$ and BCR-ABL1 ${ }^{\text {neg }}$ B ALL $[91,107]$. Elevated expression of Ik6 is frequently correlated with elevated expression of Aiol1 [105]. It has been proposed that the high level of Ikaros short isoform expression is due to genetic lesions. Supporting this idea, IKZF1 somatic deletions have been found in up to $35 \%$ of recurrences [97] and in $23.9 \%$ of the patients with elevated levels of minimal residual disease [107]. Thereby, full-length Ikaros seems to be a leukemia suppressor that is inhibited by its dominant negative isoforms [101]. The currently available information on IKZF3 expression in ALL is limited. However, Liippo et al. reported that the majority of the patients with ALL expressed several Aiolos isoforms [72]. A summary of homeostatic and leukemic expression of receptors, signaling proteins, and transcription factors along the B cell pathway is shown in Figure 3.

\section{Conclusion}

Genes critical for commitment to the B cell lineage and B cell maintenance are often mutated in B ALL. Genomewide analysis methods that measure expression levels and assess the presence of genetic and epigenetic abnormalities in B cell ALL have recently provided new insights into the genetic lesions most frequently associated with this disease. These genetic signatures are paving the way for (1) a better understanding of the origin of B cell ALL, (2) a precise classification of the disease, and (3) accurate predictive profiles, which are especially necessary for those patients that lack a high-risk associated translocation but are prone to relapse. These data will also be useful for the generation of more effective drugs that act specifically to complement or counteract the genetic lesions associated with ALL. In the near future, such drugs will have a major impact on the overall cure rates $[65,66]$.

\section{Acknowledgments}

The authors would like to thank Dr. Rosana Pelayo for her helpful comments and critical revision of the paper. Dr. P. 
Pérez-Vera and Dr. A. Reyes-León are recipients of funding FONSEC SSA/IMSS/ISSSTE//44402.

\section{References}

[1] R. L. Geahlen, “Syk and pTyr'd: signaling through the B cell antigen receptor," Biochimica et Biophysica Acta, vol. 1793, no. 7, pp. 1115-1127, 2009.

[2] E. M. Fuentes-Pananá, G. Bannish, and J. G. Monroe, "Basal B-cell receptor signaling in B lymphocytes: mechanisms of regulation and role in positive selection, differentiation, and peripheral survival," Immunological Reviews, vol. 197, pp. 2640, 2004.

[3] I. L. Mårtensson, N. Almqvist, O. Grimsholm, and A. I. Bernardi, "The pre-B cell receptor checkpoint," FEBS Letters, vol. 584, no. 12, pp. 2572-2579, 2010.

[4] E. M. Fuentes-Pananá, G. Bannish, N. Shah, and J. G. Monroe, "Basal $\operatorname{Ig} \alpha / \operatorname{Ig} \beta$ signals trigger the coordinated initiation of pre-B cell antigen receptor-dependent processes," Journal of Immunology, vol. 173, no. 2, pp. 1000-1011, 2004.

[5] L. R. Thomas, R. M. Cobb, and E. M. Oltz, "Dynamic regulation of antigen receptor gene assembly," Advances in Experimental Medicine and Biology, vol. 650, pp. 103-115, 2009.

[6] R. R. Hardy, C. E. Carmack, S. A. Shinton, J. D. Kemp, and K. Hayakawa, "Resolution and characterization of pro-B and pre-pro-B cell stages in normal mouse bone marrow," Journal of Experimental Medicine, vol. 173, no. 5, pp. 1213-1225, 1991.

[7] K. Nagata, T. Nakamura, F. Kitamura et al., "The $\operatorname{Ig} \alpha / \operatorname{Ig} \beta$ heterodimer on $\mu$-negative ProB cells is competent for transducing signals to induce early B cell differentiation," Immunity, vol. 7, no. 4, pp. 559-570, 1997.

[8] T. Yasuda, H. Sanjo, G. Pagès et al., "Erk kinases link pre-B cell receptor signaling to transcriptional events required for early B cell expansion," Immunity, vol. 28, no. 4, pp. 499-508, 2008.

[9] M. Mandal, S. E. Powers, K. Ochiai et al., "Ras orchestrates exit from the cell cycle and light-chain recombination during early B cell development," Nature Immunology, vol. 10, no. 10, pp. 1110-1117, 2009.

[10] A. Rolink, A. Kudo, H. Karasuyama, Y. Kikuchi, and F. Melchers, "Long-term proliferating early pre B cell lines and clones with the potential to develop to surface Ig-positive mitogen reactive $\mathrm{B}$ cells in vitro and in vivo," The EMBO Journal, vol. 10, no. 2, pp. 327-336, 1991.

[11] W. C. Lin and S. Desiderio, "Cell cycle regulation of V(D)J recombination-activating protein RAG-2," Proceedings of the National Academy of Sciences of the United States of America, vol. 91, no. 7, pp. 2733-2737, 1994.

[12] Z. Li, D. I. Dordai, J. Lee, and S. Desiderio, "A conserved degradation signal regulates RAG-2 accumulation during cell division and links $\mathrm{V}(\mathrm{D}) \mathrm{J}$ recombination to the cell cycle," Immunity, vol. 5, no. 6, pp. 575-589, 1996.

[13] J. Hao, F. C. Chang, A. E. Ross et al., "Ubiquitylation of RAG2 by Skp2-SCF links destruction of the V(D)J recombinase to the cell cycle," Molecular Cell, vol. 18, no. 6, pp. 699-709, 2005.

[14] M. Noguchi, Y. Nakamura, S. M. Russell et al., "Interleukin-2 receptor $\gamma$ chain: a functional component of the interleukin7 receptor," Science, vol. 262, no. 5141, pp. 1877-1880, 1993.
[15] C. D. Milne and C. J. Paige, "IL-7: a key regulator of B lymphopoiesis," Seminars in Immunology, vol. 18, no. 1, pp. 20-30, 2006.

[16] J. J. Peschon, P. J. Morrissey, K. H. Grabstein et al., "Early lymphocyte expansion is severely impaired in interleukin 7 receptor-deficient mice," Journal of Experimental Medicine, vol. 180, no. 5, pp. 1955-1960, 1994.

[17] U. Von Freeden-Jeffry, P. Vieira, L. A. Lucian, T. McNeil, S. E. G. Burdach, and R. Murray, "Lymphopenia in interleukin (IL)-7 gene-deleted mice identifies IL-7 as a nonredundant cytokine," Journal of Experimental Medicine, vol. 181, no. 4, pp. 1519-1526, 1995.

[18] X. Cao, E. W. Shores, J. Hu-Li et al., "Defective lymphoid development in mice lacking expression of the common cytokine receptor $\gamma$ chain," Immunity, vol. 2, no. 3, pp. 223238, 1995.

[19] J. P. DiSanto, W. Müller, D. Guy-Grand, A. Fischer, and K. Rajewsky, "Lymphoid development in mice with a targeted deletion of the interleukin 2 receptor $\gamma$ chain," Proceedings of the National Academy of Sciences of the United States of America, vol. 92, no. 2, pp. 377-381, 1995.

[20] K. Akashi, M. Kondo, U. Von Freeden-Jeffry, R. Murray, and I. L. Weissman, "Bcl-2 rescues T lymphopoiesis in interleukin-7 receptor-deficient mice," Cell, vol. 89, no. 7, pp. 1033-1041, 1997.

[21] E. Maraskovsky, L. A. O’Reilly, M. Teepe, L. M. Corcoran, J. J. Peschon, and A. Strasser, "Bcl-2 can rescue T lymphocyte development in Interleukin-7 receptor-deficient mice but not in mutant rag- $1^{-/-}$mice," Cell, vol. 89, no. 7, pp. 1011-1019, 1997.

[22] M. Kondo, K. Akashi, J. Domen, K. Sugamura, and I. L. Weissman, "Bcl-2 rescues $\mathrm{T}$ lymphopoiesis, but not $\mathrm{B}$ or NK cell development, in common $\gamma$ chain-deficient mice," Immunity, vol. 7, no. 1, pp. 155-162, 1997.

[23] A. Puel, S. F. Ziegler, R. H. Buckley, and W. J. Leonard, "Defective IL7R expression in TBNK severe combined immunodeficiency," Nature Genetics, vol. 20, no. 4, pp. 394397, 1998.

[24] Y. K. Parrish, I. Baez, T. A. Milford et al., "IL-7 dependence in human B lymphopoiesis increases during progression of ontogeny from cord blood to bone marrow," Journal of Immunology, vol. 182, no. 7, pp. 4255-4266, 2009.

[25] P. E. Kovanen and W. J. Leonard, "Cytokines and immunodeficiency diseases: critical roles of the $\gamma$-dependent cytokines interleukins 2, 4, 7, 9, 15, and 21, and their signaling pathways," Immunological Reviews, vol. 202, pp. 67-83, 2004.

[26] L. Hennighausen and G. W. Robinson, "Interpretation of cytokine signaling through the transcription factors STAT5A and STAT5B," Genes and Development, vol. 22, no. 6, pp. 711721, 2008.

[27] Z. Yao, Y. Cui, W. T. Watford et al., "Stat5a/b are essential for normal lymphoid development and differentiation," Proceedings of the National Academy of Sciences of the United States of America, vol. 103, no. 4, pp. 1000-1005, 2006.

[28] A. Hoelbl, B. Kovacic, M. A. Kerenyi et al., "Clarifying the role of Stat5 in lymphoid development and Abelson-induced transformation," Blood, vol. 107, no. 12, pp. 4898-4906, 2006.

[29] S. Malin, S. McManus, C. Cobaleda et al., "Role of STAT5 in controlling cell survival and immunoglobulin gene recombination during pro-B cell development," Nature Immunology, vol. 11, no. 2, pp. 171-179, 2010. 
[30] F. Ramadani, D. J. Bolland, F. Garcon et al., "The PI3K isoforms $\mathrm{p} 110 \alpha$ and $\mathrm{p} 110 \delta$ are essential for pre-B cell receptor signaling and B cell development," Science Signaling, vol. 3, no. 134, p. ra60, 2010.

[31] A. J. Marshall, H. E. Fleming, G. E. Wu, and C. J. Paige, "Modulation of the IL-7 dose-response threshold during pro$B$ cell differentiation is dependent on pre-B cell receptor expression," Journal of Immunology, vol. 161, no. 11, pp. 6038-6045, 1998.

[32] A. B. Cooper, C. M. Sawai, E. Sicinska et al., "A unique function for cyclin D3 in early B cell development," Nature Immunology, vol. 7, no. 5, pp. 489-497, 2006.

[33] J. P. Miller, D. Izon, W. DeMuth, R. Gerstein, A. Bhandoola, and D. Allman, "The earliest step in B lineage differentiation from common lymphoid progenitors is critically dependent upon interleukin 7," Journal of Experimental Medicine, vol. 196, no. 5, pp. 705-711, 2002.

[34] C. Cobaleda, A. Schebesta, A. Delogu, and M. Busslinger, "Pax5: the guardian of B cell identity and function," Nature Immunology, vol. 8, no. 5, pp. 463-470, 2007.

[35] S. L. Nutt and B. L. Kee, "The transcriptional regulation of B cell lineage commitment," Immunity, vol. 26, no. 6, pp. 715725, 2007.

[36] S. L. Nutt, B. Heavey, A. G. Rolink, and M. Busslinger, "Commitment to the B-lymphoid lineage depends on the transcription factor Pax5," Nature, vol. 401, no. 6753, pp. 556-562, 1999.

[37] E. Smith and M. Sigvardsson, "The roles of transcription factors in B lymphocyte commitment, development, and transformation," Journal of Leukocyte Biology, vol. 75, no. 6, pp. 973-981, 2004.

[38] M. O'Riordan and R. Grosschedl, “Coordinate regulation of $B$ cell differentiation by the transcription factors EBF and E2A," Immunity, vol. 11, no. 1, pp. 21-31, 1999.

[39] M. Fuxa and M. Busslinger, "Reporter gene insertions reveal a strictly B lymphoid-specific expression pattern of Pax5 in support of its B cell identity function," Journal of Immunology, vol. 178, no. 12, pp. 8222-8228, 2007.

[40] E. M. Mandel and R. Grosschedl, "Transcription control of early B cell differentiation," Current Opinion in Immunology, vol. 22, no. 2, pp. 161-167, 2010.

[41] M. Busslinger, "Transcriptional control of early B cell development," Annual Review of Immunology, vol. 22, pp. 5579, 2004.

[42] H. Sato, F. Saito-Ohara, J. Inazawa, and A. Kudo, "Pax-5 is essential for $\kappa$ sterile transcription during $\operatorname{Ig} \kappa$ chain gene rearrangement," Journal of Immunology, vol. 172, no. 8, pp. 4858-4865, 2004.

[43] E. Bertolino, K. Reddy, K. L. Medina, E. Parganas, J. Ihle, and H. Singh, "Regulation of interleukin 7-dependent immunoglobulin heavy-chain variable gene rearrangements by transcription factor STAT5," Nature Immunology, vol. 6, no. 8, pp. 836-843, 2005.

[44] M. Fuxa, J. Skok, A. Souabni, G. Salvagiotto, E. Roldan, and M. Busslinger, "Pax5 induces V-to-DJ rearrangements and locus contraction of the immunoglobulin heavy-chain gene," Genes and Development, vol. 18, no. 4, pp. 411-422, 2004.

[45] L. Y. Hsu, H. E. Liang, K. Johnson, C. Kang, and M. S. Schlissel, "Pax5 activates immunoglobulin heavy chain V to DJ rearrangement in transgenic thymocytes," Journal of Experimental Medicine, vol. 199, no. 6, pp. 825-830, 2004.
[46] A. K. Patra, T. Drewes, S. Engelmann et al., "PKB rescues calcineurin/NFAT-induced arrest of Rag expression and PreT cell differentiation," Journal of Immunology, vol. 177, no. 7, pp. 4567-4576, 2006.

[47] T. C. Kuo and M. S. Schlissel, "Mechanisms controlling expression of the RAG locus during lymphocyte development," Current Opinion in Immunology, vol. 21, no. 2, pp. 173-178, 2009.

[48] G. Bain, E. C. R. Maandag, D. J. Izon et al., "E2A proteins are required for proper $\mathrm{b}$ cell development and initiation of immunoglobulin gene rearrangements," Cell, vol. 79, no. 5, pp. 885-892, 1994.

[49] Y. Zhuang, P. Soriano, and H. Weintraub, "The helix-loophelix gene E2A is required for B cell formation," Cell, vol. 79, no. 5, pp. 875-884, 1994.

[50] K. Beck, M. M. Peak, T. Ota, D. Nemazee, and C. Murre, "Distinct roles for E12 and E47 in B cell specification and the sequential rearrangement of immunoglobulin light chain loci," Journal of Experimental Medicine, vol. 206, no. 10, pp. 2271-2284, 2009.

[51] H. Lin and R. Grosschedl, "Failure of B-cell differentiation in mice lacking the transcription factor EBF," Nature, vol. 376, no. 6537 , pp. 263-267, 1995.

[52] C. S. Seet, R. L. Brumbaugh, and B. L. Kee, "Early B cell factor promotes B lymphopoiesis with reduced interleukin 7 responsiveness in the absence of E2A," Journal of Experimental Medicine, vol. 199, no. 12, pp. 1689-1700, 2004.

[53] K. Kikuchi, A. Y. Lai, C. L. Hsu, and M. Kondo, "IL-7 receptor signaling is necessary for stage transition in adult B cell development through up-regulation of EBF," Journal of Experimental Medicine, vol. 201, no. 8, pp. 1197-1203, 2005.

[54] K. Kikuchi, H. Kasai, A. Watanabe, A. Y. Lai, and M. Kondo, "IL-7 specifies B cell fate at the common lymphoid progenitor to pre-ProB transition stage by maintaining early B cell factor expression," Journal of Immunology, vol. 181, no. 1, pp. 383-392, 2008.

[55] K. Kwon, C. Hutter, Q. Sun et al., "Instructive role of the transcription factor E2A in early B lymphopoiesis and germinal center B cell development," Immunity, vol. 28, no. 6, pp. 751-762, 2008.

[56] M. A. Thal, T. L. Carvalho, TI. He et al., "Ebf1-mediated down-regulation of Id 2 and Id 3 is essential for specification of the B cell lineage," Proceedings of the National Academy of Sciences of the United States of America, vol. 106, no. 2, pp. 552-557, 2009.

[57] S. Roessler, I. Györy, S. Imhof et al., "Distinct promoters mediate the regulation of Ebfl gene expression by interleukin-7 and Pax5," Molecular and Cellular Biology, vol. 27, no. 2, pp. 579-594, 2007.

[58] H. Maier, R. Ostraat, H. Gao et al., "Early B cell factor cooperates with Runx1 and mediates epigenetic changes associated with mb-1 transcription," Nature Immunology, vol. 5, no. 10, pp. 1069-1077, 2004.

[59] A. Schebesta, S. McManus, G. Salvagiotto, A. Delogu, G. A. Busslinger, and M. Busslinger, "Transcription factor Pax5 activates the chromatin of key genes involved in B cell signaling, adhesion, migration, and immune function," Immunity, vol. 27, no. 1, pp. 49-63, 2007.

[60] J. J. Wallin, E. R. Gackstetter, and M. E. Koshland, "Dependence of BSAP repressor and activator functions on BSAP concentration," Science, vol. 279, no. 5358, pp. 1961-1964, 1998.

[61] M. Schebesta, B. Heavey, and M. Busslinger, "Transcriptional control of B-cell development," Current Opinion in Immunology, vol. 14, no. 2, pp. 216-223, 2002. 
[62] S. L. Nutt, A. M. Morrison, P. Dörfler, A. Rolink, and M. Busslinger, "Identification of BSAP (Pax-5) target genes in early B-cell development by loss- and gain-of-function experiments," The EMBO Journal, vol. 17, no. 8, pp. 23192333, 1998.

[63] A. Souabni, C. Cobaleda, M. Schebesta, and M. Busslinger, "Pax5 promotes B lymphopoiesis and blocks T cell development by repressing Notch1," Immunity, vol. 17, no. 6, pp. 781-793, 2002.

[64] M. L. Holmes, S. Carotta, L. M. Corcoran, and S. L. Nutt, "Repression of Flt3 by Pax 5 is crucial for B-cell lineage commitment," Genes and Development, vol. 20, no. 8, pp. 933-938, 2006.

[65] M. L. Den Boer, M. van Slegtenhorst, R. X. De Menezes et al., "A subtype of childhood acute lymphoblastic leukaemia with poor treatment outcome: a genome-wide classification study," The Lancet Oncology, vol. 10, no. 2, pp. 125-134, 2009.

[66] R. C. Harvey, C. G. Mullighan, X. Wang et al., "Identification of novel cluster groups in pediatric high-risk Bprecursor acute lymphoblastic leukemia with gene expression profiling: correlation with genome-wide DNA copy number alterations, clinical characteristics, and outcome," Blood, vol. 116, no. 23, pp. 4874-4884, 2010.

[67] A. Delogu, A. Schebesta, Q. Sun, K. Aschenbrenner, T. Perlot, and M. Busslinger, "Gene repression by Pax 5 in B cells is essential for blood cell homeostasis and is reversed in plasma cells," Immunity, vol. 24, no. 3, pp. 269-281, 2006.

[68] C. Pridans, M. L. Holmes, M. Polli et al., "Identification of Pax5 target genes in early B cell differentiation," Journal of Immunology, vol. 180, no. 3, pp. 1719-1728, 2008.

[69] Á. Molnár and K. Georgopoulos, “The Ikaros gene encodes a family of functionally diverse zinc finger DNA-binding proteins," Molecular and Cellular Biology, vol. 14, no. 12, pp. 8292-8303, 1994.

[70] B. Morgan, L. Sun, N. Avitahl et al., "Aiolos, a lymphoid restricted transcription factor that interacts with Ikaros to regulate lymphocyte differentiatisn," The EMBO Journal, vol. 16, no. 8, pp. 2004-2013, 1997.

[71] K. E. Brown, S. S. Guest, S. T. Smale, K. Hahm, M. Merkenschlager, and A. G. Fisher, "Association of transcriptionally silent genes with Ikaros complexes at centromeric heterochromatin," Cell, vol. 91, no. 6, pp. 845-854, 1997.

[72] J. Liippo, K. P. Nera, E. Veistinen et al., "Both normal and leukemic B lymphocytes express multiple isoforms of the human Aiolos gene," European Journal of Immunology, vol. 31, no. 12, pp. 3469-3474, 2001.

[73] R. Caballero, F. Setien, L. Lopez-Serra et al., "Combinatorial effects of splice variants modulate function of Aiolos," Journal of Cell Science, vol. 120, no. 15, pp. 2619-2630, 2007.

[74] J. Alinikula, P. Kohonen, K.-P. Nera, and O. Lassila, "Concerted action of Helios and Ikaros controls the expression of the inositol 5-phosphatase SHIP," European Journal of Immunology, vol. 40, no. 9, pp. 2599-2607, 2010.

[75] J. H. Wang, N. Avitahl, A. Cariappa et al., "Aiolos regulates B cell activation and maturation to effector state," Immunity, vol. 9, no. 4, pp. 543-553, 1998.

[76] S. Ma, S. Pathak, M. Mandal, L. Trinh, M. R. Clark, and R. Lu, "Ikaros and Aiolos inhibit pre-B-cell proliferation by directly suppressing c-Myc expression," Molecular and Cellular Biology, vol. 30, no. 17, pp. 4149-4158, 2010.

[77] K. Georgopoulos, M. Bigby, J.-H. Wang, A. Molnar, S. Winandy, and A. Sharpe, "Early arrest in lymphocyte differentiation in ikaros mutant mice," Cell, vol. 78, pp. 143-156, 1994.
[78] S. Winandy, P. Wu, and K. Georgopoulos, "A dominant mutation in the Ikaros gene leads to rapid development of leukemia and lymphoma," Cell, vol. 83, no. 2, pp. 289-299, 1995.

[79] M. Onciu, "Acute lymphoblastic leukemia," Hematology/Oncology Clinics of North America, vol. 23, no. 4, pp. 655674, 2009.

[80] C. H. Pui, "Acute lymphoblastic leukemia: introduction," Seminars in Hematology, vol. 46, no. 1, pp. 1-2, 2009.

[81] Y. H. Kuo, R. M. Gerstein, and L. H. Castilla, "Cbf $\beta$-SMMHC impairs differentiation of common lymphoid progenitors and reveals an essential role for RUNX in early B-cell development," Blood, vol. 111, no. 3, pp. 1543-1551, 2008.

[82] K. L. Durst and S. W. Hiebert, "Mole of RUNX family members in transcriptional repression and gene silencing," Oncogene, vol. 23, no. 24, pp. 4220-4224, 2004.

[83] T. Okuda, J. Van Deursen, S. W. Hiebert, G. Grosveld, and J. R. Downing, "AML1, the target of multiple chromosomal translocations in human leukemia, is essential for normal fetal liver hematopoiesis," Cell, vol. 84, no. 2, pp. 321-330, 1996.

[84] Q. Wang, T. Stacy, M. Binder, M. Marín-Padilla, A. H. Sharpe, and N. A. Speck, "Disruption of the Cbfa2 gene causes necrosis and hemorrhaging in the central nervous system and blocks definitive hematopoiesis," Proceedings of the National Academy of Sciences of the United States of America, vol. 93, no. 8, pp. 3444-3449, 1996.

[85] A. T. Look, "Oncogenic transcription factors in the human acute leukemias," Science, vol. 278, no. 5340, pp. 1059-1064, 1997.

[86] J. R. Mcwhirter, S. T. C. Neuteboom, E. V. Wancewicz, B. P. Monia, J. R. Downing, and C. Murre, "Oncogenic homeodomain transcription factor E2A-Pbxl activates a novel WNT gene in pre-B acute lymphoblastoid leukemia," Proceedings of the National Academy of Sciences of the United States of America, vol. 96, no. 20, pp. 11464-11469, 1999.

[87] K. Hirose, T. Inukai, J. Kikuchi et al., "Aberrant induction of LMO2 by the E2A-HLF chimeric transcription factor and its implication in leukemogenesis of B-precursor ALL with t(17;19)," Blood, vol. 116, no. 6, pp. 962-970, 2010.

[88] A. V. Krivtsov, Z. Feng, M. E. Lemieux et al., "H3K79 methylation profiles define murine and human MLL-AF4 leukemias," Cancer Cell, vol. 14, no. 5, pp. 355-368, 2008.

[89] M. G. Guenther, L. N. Lawton, T. Rozovskaia et al., "Aberrant chromatin at genes encoding stem cell regulators in human mixed-lineage leukemia," Genes and Development, vol. 22, no. 24, pp. 3403-3408, 2008.

[90] N. McCarthy, "Leukaemia: MLL makes friends and influences," Nature Reviews Cancer, vol. 10, no. 8, p. 529, 2010.

[91] C. G. Mullighan, C. B. Miller, I. Radtke et al., "BCR-ABL1 lymphoblastic leukaemia is characterized by the deletion of Ikaros," Nature, vol. 453, no. 7191, pp. 110-114, 2008.

[92] S. Malin, S. McManus, and M. Busslinger, "STAT5 in B cell development and leukemia," Current Opinion in Immunology, vol. 22, no. 2, pp. 168-176, 2010.

[93] C. G. Mullighan, S. Goorha, I. Radtke et al., "Genomewide analysis of genetic alterations in acute lymphoblastic leukaemia," Nature, vol. 446, no. 7137, pp. 758-764, 2007.

[94] Y. Sadakane, M. Zaitsu, M. Nishi et al., "Expression and production of aberrant PAX5 with deletion of exon 8 in Blineage acute lymphoblastic leukaemia of children," British Journal of Haematology, vol. 136, no. 2, pp. 297-300, 2007.

[95] A. Santoro, M. G. Bica, L. Dagnino et al., "Altered mRNA expression of PAX5 is a common event in acute lymphoblastic 
leukaemia," British Journal of Haematology, vol. 146, no. 6, pp. 686-689, 2009.

[96] J. Familiades, M. Bousquet, N. Dastugue et al., "Pax5 mutations occur frequently in adult B-cell acute lymphoblastic leukemia (B-ALL) and is significantly associated with BCRABL fusion gene," Blood, vol. 110: Abstract 2806, 2007.

[97] D. Bhojwani, W. Yang, X. Cai et al., "Genome-wide copy number profiling reveals molecular evolution from diagnosis to relapse in childhood acute lymphoblastic leukemia," Blood, vol. 112, no. 10, pp. 4178-4183, 2008.

[98] Q. An, S. L. Wright, Z. J. Konn et al., "Variable breakpoints target PAX5 in patients with dicentric chromosomes: a model for the basis of unbalanced translocations in cancer," Proceedings of the National Academy of Sciences of the United States of America, vol. 105, no. 44, pp. 17050-17054, 2008.

[99] K. Paulsson, J. B. Cazier, F. MacDougall et al., "Microdeletions are a general feature of adult and adolescent acute lymphoblastic leukemia: unexpected similarities with pediatric disease," Proceedings of the National Academy of Sciences of the United States of America, vol. 105, no. 18, pp. 6708-6713, 2008.

[100] L. Sun, N. Heerema, L. Crotty et al., "Expression of dominant-negative and mutant isoforms of the antileukemic transcription factor Ikaros in infant acute lymphoblastic leukemia," Proceedings of the National Academy of Sciences of the United States of America, vol. 96, no. 2, pp. 680-685, 1999.

[101] L. Sun, P. A. Goodman, C. M. Wood et al., "Expression of aberrantly spliced oncogenic Ikaros isoforms in childhood acute lymphoblastic leukemia," Journal of Clinical Oncology, vol. 17, no. 12, pp. 3753-3766, 1999.

[102] K. Nakase, F. Ishimaru, N. Avitahl et al., "Dominant negative isoform of the Ikaros gene in patients with adult B-cell acute lymphoblastic leukemia," Cancer Research, vol. 60, no. 15, pp. 4062-4065, 2000.

[103] S. Olivero, C. Maroc, E. Beillard et al., "Detection of different Ikaros isoforms in human leukaemias using realtime quantitative polymerase chain reaction," British Journal of Haematology, vol. 110, no. 4, pp. 826-830, 2000.

[104] K. Nishii, N. Katayama, H. Miwa et al., "Non-DNA-binding Ikaros isoform gene expressed in adult B-precursor acute lymphoblastic leukemia," Leukemia, vol. 16, no. 7, pp. 12851292, 2002.

[105] M. Takanashi, T. Yagi, T. Imamura et al., "Expression of the Ikaros gene family in childhood acute lymphoblastic leukaemia," British Journal of Haematology, vol. 117, no. 3, pp. 525-530, 2002.

[106] A. N. Meleshko, L. V. Movchan, M. V. Belevtsev, and T. V. Savitskaja, "Relative expression of different Ikaros isoforms in childhood acute leukemia," Blood Cells, Molecules, and Diseases, vol. 41, no. 3, pp. 278-283, 2008.

[107] C. G. Mullighan, X. Su, J. Zhang et al., "Deletion of IKZF1 and prognosis in acute lymphoblastic leukemia," New England Journal of Medicine, vol. 360, no. 5, pp. 470-480, 2009. 


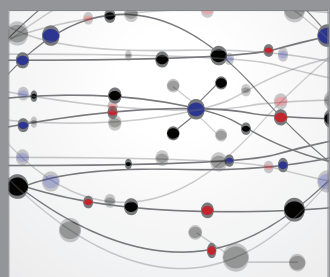

The Scientific World Journal
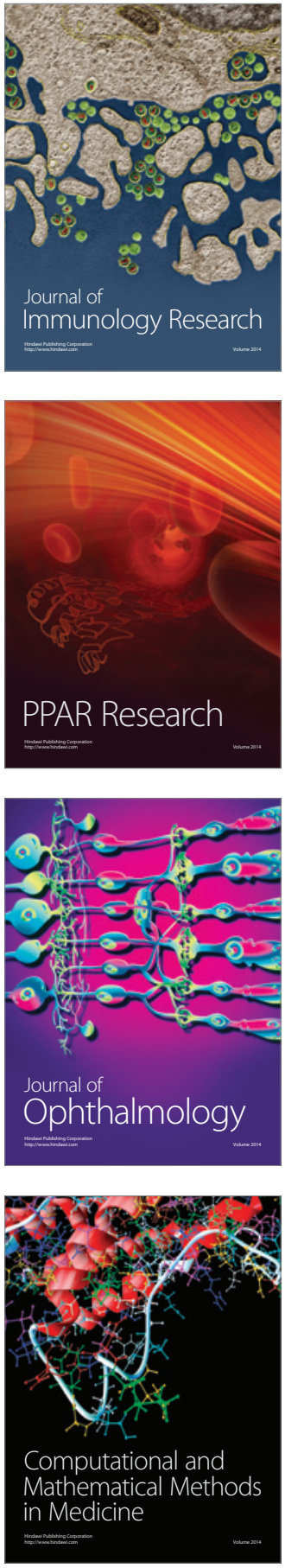

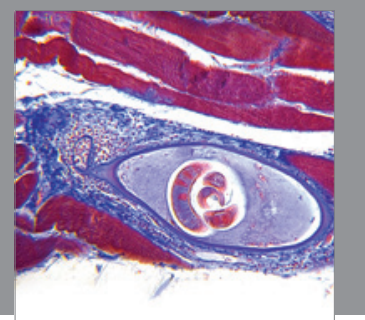

Gastroenterology

Research and Practice
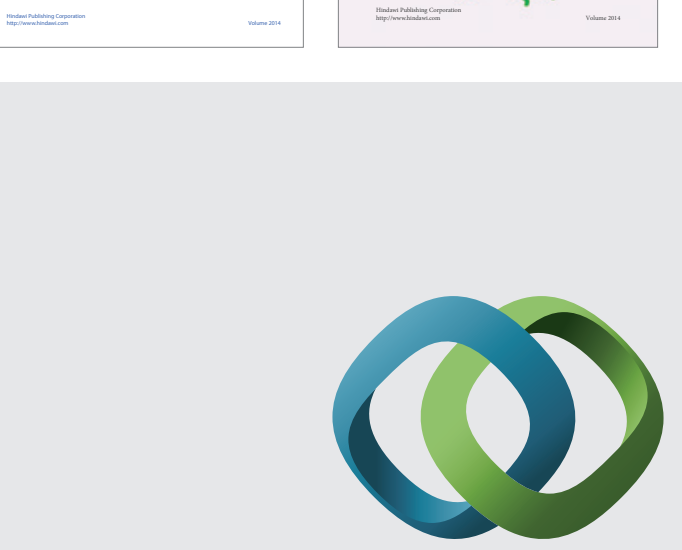

\section{Hindawi}

Submit your manuscripts at

http://www.hindawi.com
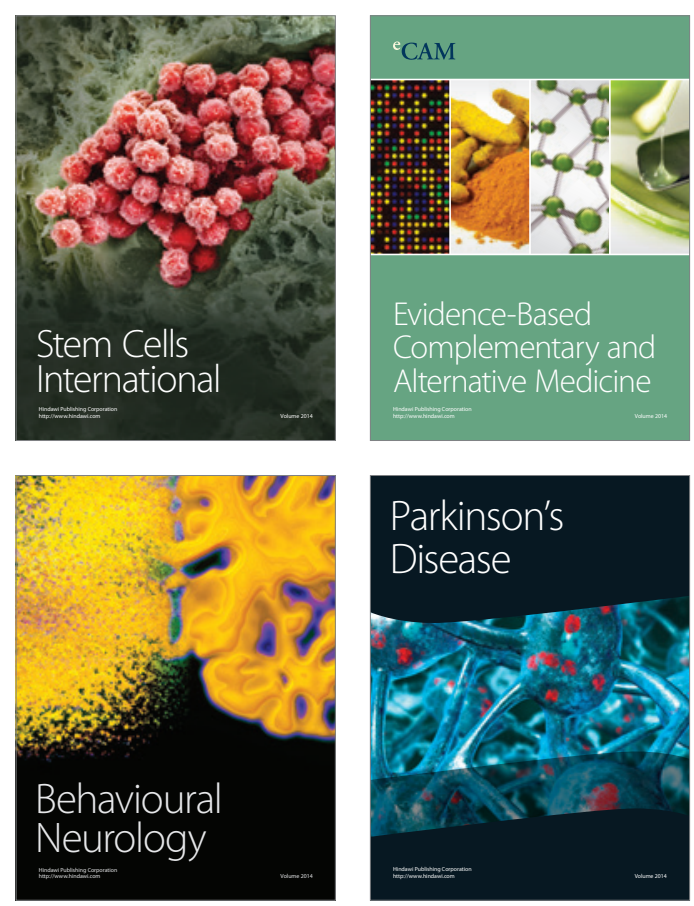

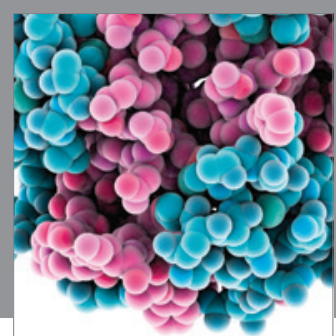

Journal of
Diabetes Research

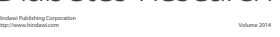

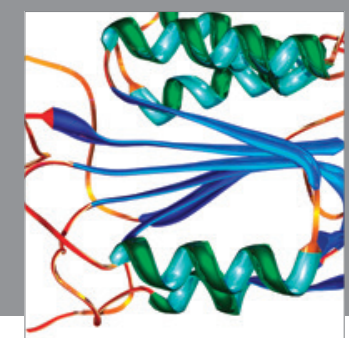

Disease Markers
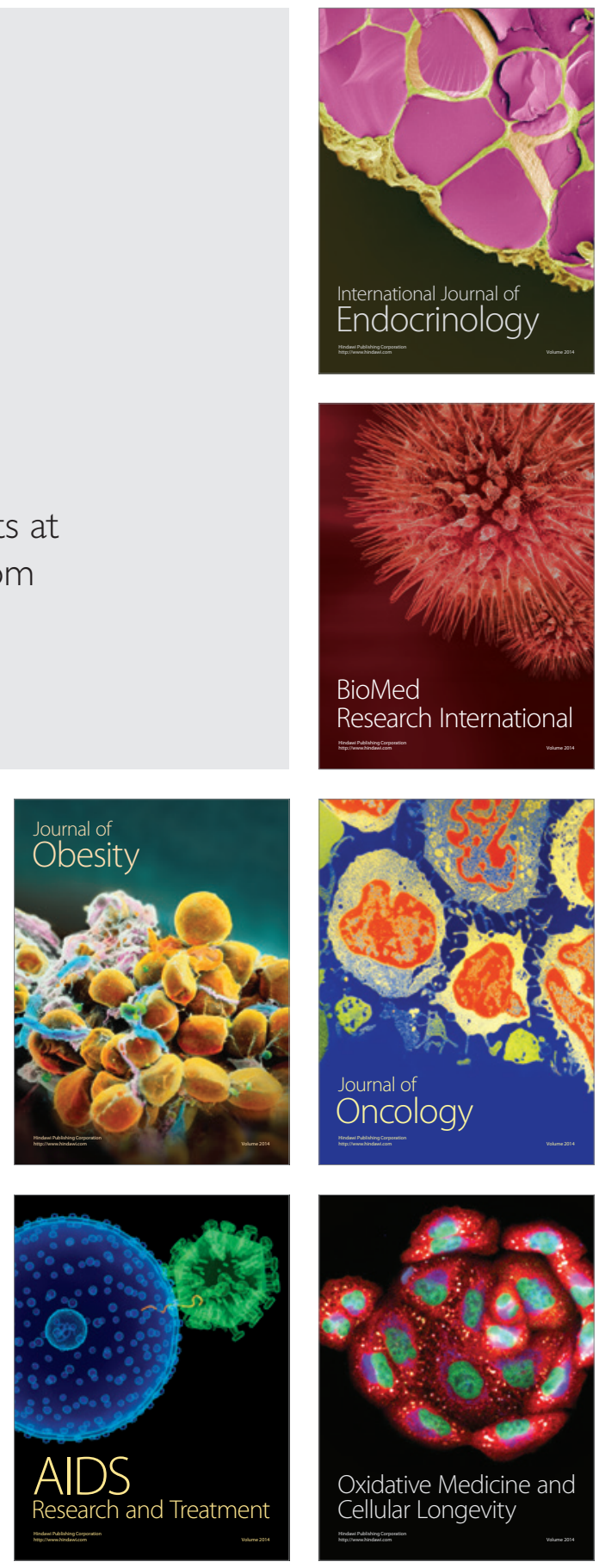